\title{
Effects of low-fat dairy consumption on markers of low-grade systemic inflammation and endothelial function in overweight and obese subjects: an intervention study
}

\author{
Leonie E. C. van Meij1* and Ronald P. Mensink \\ Department of Human Biology, NUTRIM School for Nutrition, Toxicology and Metabolism, Maastricht University Medical \\ Centre+, PO Box 616, 6200 MD Maastricht, The Netherlands \\ (Received 9 October 2009 - Revised 25 May 2010 - Accepted 26 May 2010 - First published online 28 June 2010)
}

\begin{abstract}
Although increased concentrations of plasma inflammatory markers are not one of the criteria to diagnose the metabolic syndrome, low-grade systemic inflammation is receiving large attention as a metabolic syndrome component and cardiovascular risk factor. As several epidemiological studies have suggested a negative relationship between low-fat dairy consumption and the metabolic syndrome, we decided to investigate the effects of low-fat dairy consumption on inflammatory markers and adhesion molecules in overweight and obese subjects in an intervention study. Thirty-five healthy subjects $\left(\mathrm{BMI}>27 \mathrm{~kg} / \mathrm{m}^{2}\right)$ consumed, in a random order, low-fat dairy products $(500 \mathrm{ml}$ low-fat milk and $150 \mathrm{~g}$ low-fat yogurt) or carbohydrate-rich control products $(600 \mathrm{ml}$ fruit juice and three fruit biscuits) daily for 8 weeks. Plasma concentrations of TNF- $\alpha$ were decreased by $0.16(\mathrm{SD} 0.50) \mathrm{pg} / \mathrm{ml}(P=0.070)$, and soluble TNF- $\alpha$ receptor-1 (s-TNFR-1) was increased by $110.0(\mathrm{SD} 338.4) \mathrm{pg} / \mathrm{ml}$ $(P=0.062)$ after the low-fat dairy period than after the control period. s-TNFR-2 was increased by $227 \cdot 0(\mathrm{SD} 449 \cdot 0) \mathrm{pg} / \mathrm{ml}(P=0 \cdot 020) \mathrm{by}$ the dairy intervention. As a result, the TNF- $\alpha$ index, defined as the TNF- $\alpha$ :s-TNFR-2 ratio, was decreased by 0.000053 (SD 0.00 012) $(P=0.015)$ after the dairy diet consumption. Low-fat dairy consumption had no effect on IL-6, monocyte chemoattractant protein-1, intracellular adhesion molecule- 1 and vascular cell adhesion molecule- 1 concentrations. The present results indicate that in overweight and obese subjects, low-fat dairy consumption for 8 weeks may increase concentrations of s-TNFR compared with carbohydrate-rich product consumption, but that it has no effects on other markers of chronic inflammation and endothelial function.
\end{abstract}

Low-fat dairy consumption: Inflammatory markers: Adhesion molecules

The metabolic syndrome is a metabolic disorder that strongly enhances the risk of developing CVD and type 2 diabetes mellitus. Abdominal obesity, atherogenic dyslipidaemia, hypertension, insulin resistance, a pro-thrombotic state and a low-grade pro-inflammatory state have now been identified as components of the metabolic syndrome that are related to CVD risk. Although inflammatory markers are currently not included in the ATP III or WHO diagnostic criteria for the metabolic syndrome ${ }^{(1)}$, low-grade systemic inflammation is receiving large attention as a metabolic syndrome component and cardiovascular risk factor. Inflammatory markers such as C-reactive $\operatorname{protein}^{(2)}$, IL-6 ${ }^{(3)}$, TNF- $\alpha^{(4)}$ and fibrinogen ${ }^{(5)}$, among others, have been linked to the metabolic syndrome.

The consumption of dairy products has been inversely associated with the prevalence or incidence of the metabolic syndrome in a number of epidemiological studies ${ }^{(6-12)}$. In the Coronary Artery Risk Development in Young Adults Study ${ }^{(11)}$, for example, the intake of dairy products was negatively correlated with the development of obesity, dyslipidaemia, glucose intolerance and hypertension over the next 10 years in overweight subjects. However, the relationship between dairy consumption and the chronic inflammatory state linked to the metabolic syndrome has not yet been studied in depth. Recently, Zemel \& Sun ${ }^{(13)}$ reported positive effects of dairy and $\mathrm{Ca}$ intakes on inflammatory markers, including TNF- $\alpha$, IL- 6 and adiponectin, in mice. Moreover, they observed reduced plasma concentrations of C-reactive protein and increased concentrations of plasma adiponectin in obese human subjects after the consumption of a euenergetic or hypoenergetic high-dairy diet ${ }^{(13)}$. Therefore, in the present intervention study, we investigated the effects of low-fat milk and yogurt consumption on a broad range of inflammatory markers and adhesion molecules in overweight and obese human subjects.

\section{Subjects and methods}

Subjects

The present study was conducted according to the guidelines laid down in the Declaration of Helsinki, and all procedures involving human subjects were approved by the Medical Ethics Committee of Maastricht University. Written informed

Abbreviations: $1,25-(\mathrm{OH})_{2} \mathrm{D}_{3}, 1,25$-dihydroxyvitamin $\mathrm{D}_{3}$; En $\%$, \% energy; MCP-1, monocyte chemoattractant protein-1; s-TNFR, soluble TNF- $\alpha$ receptor. 
consent was obtained from all the subjects. The study protocol has been reported in detail ${ }^{(14)}$ previously. Briefly, forty male and female subjects were recruited in Maastricht and surroundings areas through advertisements in the local newspapers and in the University Hospital newsletter, and through posters in university and hospital buildings. During the screening visits, weight, height, waist circumference and blood pressure were measured. Two fasting blood samples, separated by a $3 \mathrm{~d}$ period, were taken for the determination of serum lipid and lipoprotein concentrations. Subjects were enrolled into the study when they met the following criteria: $18-70$ years of age; BMI $>27 \mathrm{~kg} / \mathrm{m}^{2}$ or waist circumference $>88 \mathrm{~cm}$ (women) or $>102 \mathrm{~cm}$ (men); no active CVD, familial hypercholesterolaemia or other conditions that might interfere with the study outcomes; no pregnancy or breast-feeding; no abuse of alcohol or drugs; stable body weight during the past 3 months; and dairy (milk, yogurt and cheese (products)) $<500 \mathrm{~g} / \mathrm{d}$, as asked during the screening visits. Ten male and thirty female subjects were selected. Four subjects withdrew for personal reasons, and one subject was excluded from the analyses due to non-adherence to the protocol. Thirty-five subjects (ten males and twenty-five females, of which twelve were pre-menopausal and thirteen were post-menopausal) were used for the analyses. Subjects were asked not to change their dietary habits, level of physical exercise, alcohol intake, smoking habits or use of oral contraceptives during the study period.

\section{Study design and intervention}

The present study consisted of two intervention periods of 8 weeks, in a crossover design, separated by a washout period of at least 2 weeks. Subjects were randomly allocated to one of two treatment groups. The first group ( $n$ 17) consumed low-fat dairy products as a dietary supplement during the first intervention period, and carbohydrate-rich control products during the second intervention period, and for the second group of subjects ( $n$ 18), it was vice versa. The subjects maintained their habitual diet during the entire study. The dairy products consisted of $500 \mathrm{ml}$ low-fat
$(1.5 \%, w / w)$ milk and $150 \mathrm{~g}$ low-fat $(1.5 \%$, w/w) yogurt (Campina, Woerden, The Netherlands) per day. The control products consisted of $600 \mathrm{ml}$ fruit juice (Refresco, Dordrecht, The Netherlands) and $43 \mathrm{~g}$ (three pieces) fruit biscuits (Verkade, Zaandam, The Netherlands) per day. The subjects received the products in daily packages, which they had to consume throughout the day. Total energy contents of the dairy and control products were similar (Table 1). At the end of each treatment period, energy and nutrient intakes during the previous 4 weeks were estimated using a validated $\mathrm{FFQ}^{(15)}$. Subjects had to record all signs of illness, use of medication or deviations from the study protocol in a diary.

\section{Blood sampling and analyses}

At the start of each treatment period, and after 4,7 and 8 weeks, blood samples were taken after an overnight fast. Subjects were not allowed to consume alcohol during the previous day or to smoke on the morning before blood sampling. Venous blood was drawn into EDTA tubes using a Vacutainer system (Becton Dickinson, Franklin Lakes, NJ, USA). After sampling, the tubes were kept on ice and centrifuged within $1 \mathrm{~h}$ of venepuncture at $2500 \mathrm{~g}$ for $30 \mathrm{~min}$ at $4^{\circ} \mathrm{C}$, and plasma samples were snap-frozen in liquid $\mathrm{N}_{2}$ and stored at $-80^{\circ} \mathrm{C}$.

Samples collected at weeks 7 and 8 were pooled before the analysis. Plasma concentrations of TNF- $\alpha$ and IL-6 were determined using ELISA kits (R\&D Systems, Abingdon, UK). ELISA kits were also used for the measurement of plasma concentrations of monocyte chemoattractant protein1 (MCP-1) (Human MCP-1 Ultra-Sensitive Kit), soluble TNF- $\alpha$ receptors (s-TNFR) 1 and 2 (Human TNFR1 and TNFR2 Ultra-Sensitive Kit), intracellular adhesion molecule1 and vascular cell adhesion molecule-1 (Human Vascular Injury II Kit; Meso Scale Discovery, Gaithersburg, MD, USA). TNF- $\alpha$ index was calculated as $(\mathrm{TNF}-\alpha) /(\mathrm{s}-\mathrm{TNFR}-2)^{(16)}$. To test subjects' compliance, plasma concentrations of 1,25dihydroxyvitamin $\mathrm{D}_{3}\left(1,25-(\mathrm{OH})_{2} \mathrm{D}_{3}\right)$ were determined by ELISA (Immunodiagnostic Systems, Boldon, UK). 1,25$(\mathrm{OH})_{2} \mathrm{D}_{3}$ concentrations are expected to decrease when dietary

Table 1. Composition of dairy and control products

(Mean values and standard deviations)

\begin{tabular}{|c|c|c|c|c|c|c|}
\hline & \multicolumn{3}{|c|}{ Dairy } & \multicolumn{3}{|c|}{ Control } \\
\hline & \multirow[b]{2}{*}{ Product content } & \multicolumn{2}{|c|}{ Daily intake (\%) } & \multirow[b]{2}{*}{ Product content } & \multicolumn{2}{|c|}{ Daily intake (\%) } \\
\hline & & Mean & SD & & Mean & SD \\
\hline Energy (MJ) & 1.5 & $16 \cdot 3$ & $3 \cdot 7$ & 1.7 & 18.9 & 3.4 \\
\hline Protein $(\mathrm{g})$ & 24.4 & 24.0 & $5 \cdot 0$ & $2 \cdot 8$ & 3.3 & 0.7 \\
\hline Fat total $(\mathrm{g})$ & $9 \cdot 8$ & $12 \cdot 8$ & $3 \cdot 6$ & $3 \cdot 8$ & 5.5 & 1.4 \\
\hline SFA (g) & $6 \cdot 3$ & $21 \cdot 2$ & 5.9 & 1.6 & $6 \cdot 6$ & $2 \cdot 1$ \\
\hline MUFA $(g)$ & $2 \cdot 4$ & $10 \cdot 4$ & $3 \cdot 7$ & 0 & - & - \\
\hline PUFA (g) & 0.3 & $2 \cdot 0$ & 0.5 & 0.6 & 3.9 & $1 \cdot 0$ \\
\hline TFA (g) & 0.4 & 23.6 & 14.5 & 0 & - & - \\
\hline Carbohydrates (g) & $39 \cdot 7$ & $15 \cdot 7$ & $4 \cdot 3$ & $85 \cdot 0$ & $30 \cdot 6$ & $6 \cdot 0$ \\
\hline Mono- and disaccharides (g) & $39 \cdot 2$ & 30.4 & 9.9 & $70 \cdot 2$ & $45 \cdot 1$ & $11 \cdot 0$ \\
\hline Fibre (g) & 0 & & - & $2 \cdot 7$ & $12 \cdot 1$ & 3.5 \\
\hline Cholesterol (mg) & 27.5 & $13 \cdot 7$ & $3 \cdot 7$ & 0 & - & - \\
\hline $\mathrm{Ca}(\mathrm{mg})$ & 800 & 53.2 & $9 \cdot 2$ & 75 & 9.0 & 3.1 \\
\hline
\end{tabular}

TFA, trans-fatty acids. 
Ca intake is increased ${ }^{(17)}$. Samples from one subject were analysed within the same run. All intra- and inter-assay variations were $<15 \%$.

\section{Statistics}

The statistical power to detect a true difference of $10 \%$ was more than $80 \%$ for all parameters, except for IL-6. All statistical analyses were performed using SPSS 16.0 for Macintosh OS X (SPSS, Inc., Chicago, IL, USA). Differences in endpoints between dairy and control periods, which were normally distributed as indicated by the Shapiro-Wilk test, were examined by paired $t$ test analysis. Values are presented as means and standard deviations and as absolute changes (95\% CI for absolute change). A $P$ value $<0.05$ (two-sided) was considered as statistically significant. The presence of time and sequence effects was tested as described ${ }^{(18)}$. The differences between men and women were also tested by an unpaired $t$ test.

\section{Results}

\section{Subjects, dietary intakes and compliance}

Subjects were 49.5 (SD 13.2) years old, and their BMI was $32.0(\mathrm{SD} 3.8) \mathrm{kg} / \mathrm{m}^{2}$. Mean body weight at the end of the intervention periods was not different between the dairy diet $(91.1(\mathrm{SD} \mathrm{13} \cdot 1) \mathrm{kg})$ and the control diet $(91.3(\mathrm{SD} \mathrm{13.5)} \mathrm{kg}$; $P=0.561)$.

The mean dietary intakes in the dairy and control periods were estimated from an FFQ. The exchange of low-fat dairy products for the carbohydrate-rich control products was reflected in the changes in the intakes of protein $(19.9$ (SD 3.2) v. 16.0 (SD 2.4) \% energy (En\%)), total fat $(33.1 \quad(\mathrm{SD} 4.7) \quad v .29 .9 \quad(\mathrm{SD} 4.9) \mathrm{En} \%)$, SFA $(12.8$ $(\mathrm{SD} 2 \cdot 1)$ v. 10.7 (SD 2.1) En\%), MUFA (10.3 (SD 1.9) $v$. 9.2 (SD 1.9) En\%), carbohydrates (45.9 (SD 6.1) v. 52.5 (SD 5.8) En\%), fibre (2.3 (SD 0.6) v. 2.6 (SD 0.7) g/MJ), cholesterol (23.3 (SD 5.6) v. $19.7(\mathrm{SD} 4.5) \mathrm{mg} / \mathrm{MJ})$ and $\mathrm{Ca}(1550$ (SD 281) v. 931 (SD 291) mg) (all $P<0 \cdot 05$ ). Total energy intake was not different between the dairy and control interventions.

Plasma concentrations of $1,25-(\mathrm{OH})_{2} \mathrm{D}_{3}$ were significantly lower at the end of the dairy period (119 (SD 30) pmol/l) than at the end of the control period (128 (SD 37) pmol/l; $P=0.034)$.

\section{Inflammatory markers and adhesion molecules}

Concentrations of plasma IL-6 were not different between the dairy and control periods (Table 2), while concentrations of TNF- $\alpha$ tended to be lower after dairy diet consumption $(P=0 \cdot 070)$. Concentrations of s-TNFR-1 tended to be higher after dairy diet consumption $(P=0.062)$, and concentrations of s-TNFR-2 were significantly higher after the dairy diet consumption than after the control diet consumption $(P=0 \cdot 020)$. Although the change in s-TNFR-1 was not statistically significant, it was correlated with the change in s-TNFR-2 (Pearson $r$ 0.692, $P<0.001)$. Calculated TNF- $\alpha$ index was lower after dairy consumption than after control consumption $(P=0 \cdot 015)$. Dairy consumption had no effect on plasma concentrations of MCP-1, intracellular adhesion molecule-1 and vascular cell adhesion molecule- 1 .

No time or sequence effects were present, and responses did not differ between men and women.

\section{Discussion}

Data from the present study indicate that low-fat dairy consumption for 8 weeks may affect markers reflecting low-grade systemic inflammation in overweight and obese subjects. We found a significant increase in plasma s-TNFR-2 concentrations after low-fat dairy consumption, while there was a trend towards higher s-TNFR-1 and lower TNF- $\alpha$ concentrations. Subjects' compliance was confirmed by the expected decrease in plasma concentrations of $1,25-(\mathrm{OH})_{2} \mathrm{D}_{3}$.

Elevated concentrations of TNF- $\alpha$ have been found to be related to obesity, insulin resistance and the metabolic syndrome $^{(19,20)}$. An enlarged adipose tissue mass increases the production of TNF- $\alpha$, which may in turn cause insulin resistance by affecting signalling pathways in different organs. Although animal studies have established TNF- $\alpha$ as a link between obesity and insulin resistance ${ }^{(21,22)}$, evidence from human studies is less conclusive. Reduced insulininduced glucose uptake after TNF- $\alpha$ infusion has been shown in healthy subjects ${ }^{(23)}$. Furthermore, the use of antiTNF- $\alpha$ drugs in inflammatory conditions induced a concomitant improvement in insulin sensitivity in several human trials $^{(24-26)}$, whereas no beneficial effects of TNF- $\alpha$ neutralisation on insulin sensitivity were found in other studies ${ }^{(27-29)}$. Furthermore, the function of s-TNFR (1 and 2) is not yet fully

Table 2. Effects of dairy consumption on inflammatory markers and adhesion molecules

(Mean values, standard deviations and $95 \%$ confidence intervals)

\begin{tabular}{|c|c|c|c|c|c|c|c|c|}
\hline & \multicolumn{2}{|c|}{ Dairy } & \multicolumn{2}{|c|}{ Control } & \multicolumn{2}{|c|}{ Change } & \multirow[b]{2}{*}{$95 \% \mathrm{Cl}$} & \multirow[b]{2}{*}{$P$} \\
\hline & Mean & SD & Mean & SD & Mean & SD & & \\
\hline s-TNFR-1 (pg/ml) & 3729 & 853 & 3619 & 769 & $110 \cdot 4$ & 338.4 & $-5 \cdot 77,226 \cdot 7$ & 0.062 \\
\hline s-TNFR-2 (pg/ml) & 4367 & 1359 & 4140 & 1122 & $227 \cdot 0$ & $549 \cdot 0$ & $38 \cdot 4,415 \cdot 6$ & 0.020 \\
\hline TNF- $\alpha(\mathrm{pg} / \mathrm{ml})$ & $2 \cdot 32$ & 0.64 & $2 \cdot 48$ & 0.76 & -0.16 & 0.50 & $-0.33,0.01$ & 0.070 \\
\hline TNF- $\alpha$ index & 0.00057 & 0.00021 & 0.00062 & 0.00020 & -0.000053 & 0.00012 & $-0.000096,-0.000011$ & 0.015 \\
\hline IL-6 (pg/ml) & 3.01 & 3.47 & 3.05 & 3.24 & -0.04 & 1.46 & $-0.54,0.46$ & 0.875 \\
\hline MCP-1 (pg/ml) & $291 \cdot 1$ & 68.5 & $289 \cdot 7$ & $66 \cdot 5$ & 1.45 & 29.4 & $-8.64,11.5$ & 0.772 \\
\hline ICAM-1 (ng/ml) & 280.5 & 78.6 & 286.9 & $86 \cdot 6$ & -6.43 & $27 \cdot 7$ & $-15.9,3.07$ & 0.178 \\
\hline VCAM-1 (ng/ml) & $447 \cdot 7$ & $110 \cdot 0$ & $436 \cdot 1$ & $103 \cdot 1$ & $11 \cdot 6$ & $76 \cdot 4$ & $-14 \cdot 7,37 \cdot 8$ & 0.377 \\
\hline
\end{tabular}

S-TNFR, soluble TNF- $\alpha$ receptor; MCP-1, monocyte chemoattractant protein-1; ICAM-1, intracellular adhesion molecule-1; VCAM-1, vascular cell adhesion molecule-1. 
understood. Elevated concentrations of s-TNFR have been associated with obesity ${ }^{(30,31)}$, and weight loss has been found to decrease TNF- $\alpha$ and increase s-TNFR concentrations $^{(32)}$. The membrane-bound forms of the two TNF receptors activate different intracellular pathways upon TNF- $\alpha$ binding, facilitating its physiological effects ${ }^{(33)}$. On the contrary, circulating TNF receptors are able to compete for TNF- $\alpha$ binding with the cell surface receptors, and have been proposed to function as inhibitors of TNF- $\alpha$ action. Through the formation of high affinity complexes and subsequent reduction of the amount of active TNF- $\alpha$, they might protect against the potentially harmful effects of $\mathrm{TNF}-\alpha^{(34,35)}$. Illustratively, a dimeric recombinant form of s-TNFR-2, known as etanercept, is often used in inflammatory conditions such as rheumatoid arthritis and psoriasis, and has been shown to improve inflammatory conditions in patients with the metabolic syndrome ${ }^{(27)}$. Our data show increased concentrations of s-TNFR-2 after low-fat dairy consumption, which might imply lower biological availability of TNF- $\alpha$ protein. In fact, when we calculated the TNF- $\alpha$ index, a measure for biologically available $\mathrm{TNF}-\alpha^{(16)}$, we found reduced numbers after the dairy intervention. Thus far, the effect of dairy products on the TNF- $\alpha$ pathway in human subjects has not been explored. Experiments in mice have indicated that $\mathrm{Ca}$ and dairy products may reduce $\mathrm{TNF}-\alpha$ production $^{(13,36)}$, but effects in human subjects have not been studied before. The present results might imply beneficial effects of low-fat dairy consumption on TNF- $\alpha$ action, but the precise consequences of these observations have to be examined further. It might be interesting for future research to study the effects of dairy intake on the activity, besides the concentration, of TNF- $\alpha$ and related parameters, since signalling from the TNF- $\alpha$ receptor has been found to be modulated by $\mathrm{Ca}$-dependent proteins ${ }^{(37)}$.

Other inflammatory markers and adhesion molecules, however, were not affected by dairy consumption. Studies addressing the effects of dairy products or their constituents on inflammation or endothelial function are scarce. Wennersberg et $a{ }^{(38)}$ studied the effects of 6-month dairy consumption in overweight men and women, and found no differences in the markers of inflammation (IL-6, C-reactive protein and $\mathrm{TNF}-\alpha$ ) and endothelial dysfunction (E-selectin and von Willebrand factor), except for a decrease in vascular cell adhesion molecule-1, which was only present in women. Zemel \& Sun ${ }^{(13)}$ reported reductions in plasma TNF- $\alpha$ and IL-6, and an increase in plasma adiponectin in mice fed a high-dairy diet. They also evaluated samples from obese men and women who followed a high-dairy euenergetic or hypoenergetic diet for 4 weeks. Compared with a low-dairy group, they observed decreased concentrations of C-reactive protein and increased concentrations of adiponectin consumption of high-dairy diets. Although the effects of an improved body composition cannot be fully excluded, they also suggested a role for the suppression of $1,25-(\mathrm{OH})_{2} \mathrm{D}_{3}$. In previous in vitro experiments, they showed that $1,25-(\mathrm{OH})_{2} \mathrm{D}_{3}$ stimulated TNF- $\alpha$ and IL- 6 expression ${ }^{(39,40)}$. On the contrary, other in vitro and animal studies provide evidence that $1,25-(\mathrm{OH})_{2} \mathrm{D}_{3}$ has anti-inflammatory properties ${ }^{(41-43)}$. In the present study, concentrations of $1,25-(\mathrm{OH})_{2} \mathrm{D}_{3}$ were measured as marker of dietary compliance and were indeed reduced by dairy consumption, but the role in the modulation of the TNF pathway remains to be elucidated. Recently, Zemel et al. ${ }^{(44)}$ showed that a euenergetic dairy-rich diet reduced inflammatory markers (IL-6, TNF- $\alpha$ and MCP-1) and increased adiponectin in overweight and obese subjects than a soyarich diet, in the absence of changes in adiposity. Effects were already present after $7 \mathrm{~d}$ of intervention, and were even more pronounced after $28 \mathrm{~d}$. The present results suggest that effects on TNF- $\alpha$-related parameters are still present after an 8-week intervention period. However, whether these changes are present for a longer period needs further study. Furthermore, unlike Zemel et al. ${ }^{(44)}$, we observed no effects on IL-6 and MCP-1, for which we have no obvious explanation.

Taken together, the present results indicate that low-fat dairy consumption for 8 weeks, compared with carbohydrate-rich product consumption, may modulate TNF- $\alpha$ signalling by increasing s-TNFR-2, but that it does not affect other markers of low-grade systemic inflammation and endothelial function in overweight and obese subjects.

\section{Acknowledgements}

There are no conflicts of interest. The present work was supported by the Dutch Dairy Association (Nederlandse Zuivel Organisatie). We would like to thank Carla Langejan and Martine Hulsbosch for their technical support, and Kirsten Cardone and Pia Peeters for their dietary assistance. L. E. C. v. M. conducted the study, analysed the data and wrote the manuscript. R. P. M. designed the study, helped in analysing the data and writing the manuscript, and had overall responsibility for the study.

\section{References}

1. Grundy SM, Brewer HB Jr, Cleeman JI, et al. (2004) Definition of metabolic syndrome: report of the National Heart, Lung, and Blood Institute/American Heart Association conference on scientific issues related to definition. Circulation 109, 433-438.

2. Tamakoshi K, Yatsuya H, Kondo T, et al. (2003) The metabolic syndrome is associated with elevated circulating C-reactive protein in healthy reference range, a systemic low-grade inflammatory state. Int J Obes Relat Metab Disord 27, 443-449.

3. Pickup JC, Mattock MB, Chusney GD, et al. (1997) NIDDM as a disease of the innate immune system: association of acute-phase reactants and interleukin-6 with metabolic syndrome X. Diabetologia 40, 1286-1292.

4. Hotamisligil GS, Arner P, Caro JF, et al. (1995) Increased adipose tissue expression of tumor necrosis factor-alpha in human obesity and insulin resistance. J Clin Invest 95, 2409-2415.

5. Ford ES (2003) The metabolic syndrome and C-reactive protein, fibrinogen, and leukocyte count: findings from the Third National Health and Nutrition Examination Survey. Atherosclerosis 168, 351-358.

6. Azadbakht L, Mirmiran P, Esmaillzadeh A, et al. (2005) Dairy consumption is inversely associated with the prevalence of the metabolic syndrome in Tehranian adults. Am J Clin Nutr 82, 523-530.

7. Beydoun MA, Gary TL, Caballero BH, et al. (2008) Ethnic differences in dairy and related nutrient consumption among US adults and their association with obesity, central obesity, and the metabolic syndrome. Am J Clin Nutr 87, 1914-1925. 
8. Elwood PC, Pickering JE \& Fehily AM (2007) Milk and dairy consumption, diabetes and the metabolic syndrome: the Caerphilly prospective study. J Epidemiol Community Health 61, 695-698.

9. Lutsey PL, Steffen LM \& Stevens J (2008) Dietary intake and the development of the metabolic syndrome: the Atherosclerosis Risk in Communities study. Circulation 117, 754-761.

10. Mennen LI, Lafay L, Feskens EJM, et al. (2000) Possible protective effect of bread and dairy products on the risk of the metabolic syndrome. Nutr Res 20, 335-347.

11. Pereira MA, Jacobs DR Jr, Van Horn L, et al. (2002) Dairy consumption, obesity, and the insulin resistance syndrome in young adults: the CARDIA Study. JAMA 287, 2081-2089.

12. Ruidavets JB, Bongard V, Dallongeville J, et al. (2007) High consumptions of grain, fish, dairy products and combinations of these are associated with a low prevalence of metabolic syndrome. J Epidemiol Community Health 61, $810-817$

13. Zemel MB \& Sun X (2008) Dietary calcium and dairy products modulate oxidative and inflammatory stress in mice and humans. J Nutr 138, 1047-1052.

14. van Meijl LE \& Mensink RP (2010) Low-fat dairy consumption reduces systolic blood pressure, but does not improve other metabolic risk parameters in overweight and obese subjects. Nutr Metab Cardiovasc Dis (Epublication ahead of print version 11 February 2010).

15. Plat J \& Mensink RP (2000) Vegetable oil based versus wood based stanol ester mixtures: effects on serum lipids and hemostatic factors in non-hypercholesterolemic subjects. Atherosclerosis 148, 101-112.

16. Barash J, Dushnitzki D, Barak Y, et al. (2003) Tumor necrosis factor (TNF)alpha and its soluble receptor (sTNFR) p75 during acute human parvovirus B19 infection in children. Immunol Lett 88, 109-112.

17. Zemel MB (2003) Mechanisms of dairy modulation of adiposity. $J$ Nutr 133, 252S-256S.

18. Pocock SJ (1983) Clinical Trials. A Practical Approach. Hoboken, NJ: John Wiley \& Sons.

19. Eckel RH, Grundy SM \& Zimmet PZ (2005) The metabolic syndrome. Lancet 365, 1415-1428.

20. Fernandez-Real JM \& Ricart W (2003) Insulin resistance and chronic cardiovascular inflammatory syndrome. Endocr Rev 24, 278-301.

21. Hotamisligil GS, Shargill NS \& Spiegelman BM (1993) Adipose expression of tumor necrosis factor-alpha: direct role in obesity-linked insulin resistance. Science 259, 87-91.

22. Uysal KT, Wiesbrock SM, Marino MW, et al. (1997) Protection from obesity-induced insulin resistance in mice lacking TNF-alpha function. Nature 389, 610-614.

23. Plomgaard P, Bouzakri K, Krogh-Madsen R, et al. (2005) Tumor necrosis factor-alpha induces skeletal muscle insulin resistance in healthy human subjects via inhibition of Akt substrate 160 phosphorylation. Diabetes 54, 2939-2945.

24. Gonzalez-Gay MA, De Matias JM, Gonzalez-Juanatey C, et al. (2006) Anti-tumor necrosis factor-alpha blockade improves insulin resistance in patients with rheumatoid arthritis. Clin Exp Rheumatol 24, 83-86.

25. Kiortsis DN, Mavridis AK, Vasakos S, et al. (2005) Effects of infliximab treatment on insulin resistance in patients with rheumatoid arthritis and ankylosing spondylitis. Ann Rheum Dis 64, 765-766.

26. Tam LS, Tomlinson B, Chu TT, et al. (2007) Impact of TNF inhibition on insulin resistance and lipids levels in patients with rheumatoid arthritis. Clin Rheumatol 26, 1495-1498.
27. Bernstein LE, Berry J, Kim S, et al. (2006) Effects of etanercept in patients with the metabolic syndrome. Arch Intern Med 166, 902-908.

28. Dominguez H, Storgaard H, Rask-Madsen C, et al. (2005) Metabolic and vascular effects of tumor necrosis factor-alpha blockade with etanercept in obese patients with type 2 diabetes. $J$ Vasc Res 42, 517-525.

29. Paquot N, Castillo MJ, Lefebvre PJ, et al. (2000) No increased insulin sensitivity after a single intravenous administration of a recombinant human tumor necrosis factor receptor: Fc fusion protein in obese insulin-resistant patients. J Clin Endocrinol Metab 85, 1316-1319.

30. Fernandez-Real JM, Broch M, Ricart W, et al. (1998) Plasma levels of the soluble fraction of tumor necrosis factor receptor 2 and insulin resistance. Diabetes 47, 1757-1762.

31. Moon YS, Kim DH \& Song DK (2004) Serum tumor necrosis factor-alpha levels and components of the metabolic syndrome in obese adolescents. Metabolism 53, 863-867.

32. Zahorska-Markiewicz B, Olszanecka-Glinianowicz $\mathrm{M}$, Janowska J, et al. (2008) The effect of weight loss on serum concentrations of FAS and tumour necrosis factor alpha in obese women. Endokrynol Pol 59, 18-22.

33. Warzocha K \& Salles G (1998) The tumor necrosis factor signaling complex: choosing a path toward cell death or cell proliferation. Leuk Lymphoma 29, 81-92.

34. Aderka D, Englemann H, Hornik V, et al. (1991) Increased serum levels of soluble receptors for tumor necrosis factor in cancer patients. Cancer Res 51, 5602-5607.

35. Van Zee KJ, Kohno T, Fischer E, et al. (1992) Tumor necrosis factor soluble receptors circulate during experimental and clinical inflammation and can protect against excessive tumor necrosis factor alpha in vitro and in vivo. Proc Natl Acad Sci U S A 89, 4845-4849.

36. Zhu Y, Mahon BD, Froicu M, et al. (2005) Calcium and 1 alpha,25-dihydroxyvitamin $\mathrm{D}_{3}$ target the TNF-alpha pathway to suppress experimental inflammatory bowel disease. Eur $J$ Immunol 35, 217-224.

37. Tomsig JL, Sohma H \& Creutz CE (2004) Calcium-dependent regulation of tumour necrosis factor-alpha receptor signalling by copine. Biochem J 378, 1089-1094.

38. Wennersberg MH, Smedman A, Turpeinen AM, et al. (2009) Dairy products and metabolic effects in overweight men and women: results from a 6-mo intervention study. Am J Clin Nutr 90, 960-968.

39. Sun X \& Zemel MB (2007) Calcium and 1,25-dihydroxyvitamin $\mathrm{D}_{3}$ regulation of adipokine expression. Obesity (Silver Spring) 15, 340-348.

40. Sun X \& Zemel MB (2008) Calcitriol and calcium regulate cytokine production and adipocyte-macrophage cross-talk. J Nutr Biochem 19, 392-399.

41. Ardizzone S, Cassinotti A, Trabattoni D, et al. (2009) Immunomodulatory effects of 1,25-dihydroxyvitamin $\mathrm{D}_{3}$ on TH1/TH2 cytokines in inflammatory bowel disease: an in vitro study. Int J Immunopathol Pharmacol 22, 63-71.

42. Prabhu Anand S, Selvaraj P \& Narayanan PR (2009) Effect of 1,25 dihydroxyvitamin $\mathrm{D}_{3}$ on intracellular IFN-gamma and TNF-alpha positive $\mathrm{T}$ cell subsets in pulmonary tuberculosis. Cytokine 45, 105-110.

43. Tang J, Zhou R, Luger D, et al. (2009) Calcitriol suppresses antiretinal autoimmunity through inhibitory effects on the Th17 effector response. J Immunol 182, 4624-4632.

44. Zemel MB, Sun X, Sobhani T, et al. (2010) Effects of dairy compared with soy on oxidative and inflammatory stress in overweight and obese subjects. Am J Clin Nutr 91, 16-22. 